\title{
DETECTION AND ANALYSIS OF EARLY GENES OF WHITE SPOT SYNDROME VIRUS IN PENAEID SHRIMP
}

\author{
Dinesh. S ${ }^{1}$, Roohi Fatima. M${ }^{1}$, Komal B Patil ${ }^{1}$, Kanika Verma ${ }^{1}$, Noopur Gupta ${ }^{1}$, Liz \\ Thenamkodath $^{1}$, Priyanka Menon ${ }^{1}$, Mekata. $\mathbf{T}^{2}$, Itami. $\mathbf{T}^{3}$, Sudhakaran. $\mathbf{R}^{1^{*}}$ \\ ${ }^{1}$ Aquaculture Biotechnology Laboratory, School of Biosciences and Technology, \\ VIT University, Vellore - 632 014, Tamilnadu, India \\ ${ }^{2}$ Aquatic Animal Health Division, National Research Institute of Aquaculture, \\ Fisheries Research Agency, Oita 879-2602, Japan \\ ${ }^{3}$ Faculty of Agriculture, Miyazaki University, Miyazaki 889-2192, Japan \\ E-mail: 2sudha@gmail.com/sudhakaran.r@vit.ac.in
}

Received: 16-2-2015

\begin{abstract}
White spot syndrome virus (WSSV) is the most lethal pathogenic virus affecting the penaeid shrimp. Outbreak of WSSV causes high mortality among the populations of cultured penaeid shrimp. Aim of the present study was to diagnose the WSSV in early stage of infection. Immediate early genes are genes that are activated due to presence of cellular stimuli and have significant role in replication and proliferation of virus. In this study, wsv303 and wsv477 genes were chosen for analysis. This study demonstrates the detection of WSSV using primers designed from early genes and sequences the Indian isolates for homology analysis. Polymerase chain reaction was performed for the detection confirmation and the PCR products were cloned. Different organs such as gill, head soft tissue, heart tissue, intestine and tail tissue had been used for the PCR assay. Both genes were amplified at the size of $420 \mathrm{bp}$ and $457 \mathrm{bp}$, respectively. Different duration samples of WSSV post-infection muscle DNAs were analyzed with the two primers and compared with OIE-nested PCR method convincing the early detecting ability of the virus. Sequencing analysis was performed with other isolates from France, China, The Netherlands and Taiwan. Phylogenetic analysis revealed that the Indian isolate was closely related to other isolates.
\end{abstract}

Keywords: White spot syndrome virus, high mortality, early gene, wsv303 and wsv477 genes, Penaeid shrimp, single step PCR, the Indian isolate.

\section{INTRODUCTION}

All over the world White Spot Disease (WSD) is the most pathogenic viral disease in cultured shrimp [1]. White spot syndrome virus (WSSV) is the causative agent of WSD. It first appeared in Asia in the year 1992. WSSV spread globally and caused serious economic losses to shrimp industries [2]. It has wide host range including many species of shrimps, crabs, crayfish and copepods [3]. The mortality rates are very high in all major species of cultivated shrimps up to 90 - $100 \%$ within 3 10 days [4]. WSSV was classified into the family called Nimaviridae. It is a rod-shaped, enveloped, double-stranded DNA virus of $300 \mathrm{~kb}$ in size and has approximately 180 open reading frames that encode approximately 59 structural proteins [5].

Generally three major functions of viral envelope proteins commonly happen in the virus host interactions, such as recognition and attachment to receptors on the host cell followed 
by penetration. Later viral genes are expressed in three different ways, the early genes are expressed prior to DNA replication, and the intermediate and late genes are expressed after DNA replication process $[1,6]$. The immediate early genes are synthesized immediately after the virus infects the host cell [7].

Early genes mainly encode regulatory proteins and they regulate the gene expression to synthesize DNA replication. Once the immediate early gene is expressed during the infection, the products from the expressed gene may function as regulatory trans-acting factors and then initiate the viral replicative process [8]. Usually the viral early genes are synthesized before 5 to 6 hours post-infection (h.p.i), later they encode regulatory proteins to regulate the process of intermediate and late gene expressions [9]. After the WSSV whole genome sequencing, nowadays researchers focus their research on analysing the structural proteins and functions of early genes. Already the functions some WSSV nucleocapsid proteins (vp15, vp24, and vp35) and envelope proteins (vp19, vp22, vp28, vp281, and vp466) have been identified and studied [10].

Till date no effective protective method has been developed against WSSV infection, because WSSV are easily spread in the environment of shrimp farms (soil, water, and other materials used for the farm maintenance) [11]. Therefore early detection of WSSV is very useful to shrimp industries. Many diagnostic tools have been developed for the detection of WSSV, which include histopathology, immunological methods like ELISA, Western blotting and many PCR methods have also been described for WSSV [3]. The World Organisation for Animal Health (OIE) adopted a nested-PCR protocol based on the reports of Lo et al. (1996a, 1996b) [12, 13] for the detection of WSSV (OIE 2013). These techniques have limitations of speed, sensitivity and specificity to diagnose WSSV infection in early stage. Single step PCR can be used to amplify selected DNA sequence and this may be used as a better diagnostic method for the identification and detection of the viral particles. Identification of WSSV early genes are helpful to diagnose the disease at initial stage of infection [14]. In the present study, a simple PCR based diagnostic method has been developed to detect WSSV in the early stage of infection and compared with standard OIE nested-PCR method.

\section{MATERIALS AND METHODS}

\section{Collection and maintenance of shrimp}

Healthy Penaeus monodon (14 - 20 g body weight) were collected from grow-out ponds located in Minjur near Chennai, Tamil Nadu, India and were maintained in fibreglass tanks with proper aeration and natural seawater at room temperature. Shrimps were fed with artificial pellet feed (CP feed, Thailand). Temperature, $\mathrm{pH}$, salinity and dissolved oxygen were properly recorded. The animals were maintained for acclimatization for about one week before the experiments.

\section{Preparation of viral inoculums}

WSSV-infected shrimp P. monodon were collected from shrimp farm located at Chennai, India. Hemolymph was collected directly from the heart of shrimp using sterile $5 \mathrm{~mL}$ syringe (22 gauge needle), transferred in $1.5 \mathrm{~mL}$ centrifuge tubes then centrifuged at $3000 \times \mathrm{g}$ for 20 mins at $4^{0} \mathrm{C}$. The supernatant fluid was recentrifuged at $8000 \times \mathrm{g}$ for $30 \mathrm{mins}$ at $4^{0} \mathrm{C}$ and final supernatant fluid was filtered through $0.2 \mu \mathrm{m}$ filter. The filtrate was stored at $-20^{\circ} \mathrm{C}$ for infectivity experiments.

\section{Experimental WSSV infection in shrimp}

The WSSV viral inoculum $5 \mu \mathrm{L}$ (300 $\mu \mathrm{g}$ of total protein) was injected intramuscularly to the second abdominal segment of the shrimps. For control, hemolymph collected from uninfected animals was injected to the control shrimps. Shrimps from both the control and infected groups were sacrificed at moribund stage. Head, gills, heart, intestine and tail were dissected from both the groups and stored individually at $-20^{\circ} \mathrm{C}$ for further studies.

\section{WSSV-DNA extraction}

WSSV-DNA was extracted from the different organs (head, gills, heart, intestine and tail) of experimentally infected shrimp by Guanidine Hydrochloride method [15]. Fifty $\mathrm{mg}$ of infected tissue was homogenized well with $1 \mathrm{~mL}$ of guanidine hydrochloride buffer $(6$ 
$\mathrm{M}$ guanidine hydrochloride, $10 \mathrm{mM}$ Tris $\mathrm{HCl}$, $0.1 \mathrm{M}$ sodium acetate and 0.1 M EDTA, pH 8.0) and allowed to react for $10 \mathrm{~min}$. After that, it was transferred to a $1.5 \mathrm{~mL}$ microfuge tube and incubated at room temperature for 30 mins.

After incubation, it was centrifuged at 5000 $\times \mathrm{g}$ for 5 mins. After spin, the supernatant fluid was transferred into a fresh microfuge tube and equal amount of ice cold absolute ethanol was added and mixed by inverting few times and kept for centrifugation at $14000 \times \mathrm{g}$ for 20 mins. The pellet were washed twice with $95 \%$ ethanol followed by dried in a vacuum drier and dissolved in $50 \mu \mathrm{L}$ sterile distilled water. The extracted viral DNA was quantified by taking the OD at $260 \mathrm{~nm}$ using UV spectrophotometer (ELICO, India). Briefly, $5 \mu \mathrm{L}$ of DNA was diluted with $995 \mu \mathrm{L}$ of sterile distilled water and the OD value at $260 \mathrm{~nm}$ was measured. Concentration of DNA was determined by multiplying the 260 OD value by 200 (dilution factor) and 50 (1 OD260 Unit $=50 \mu \mathrm{g} / \mathrm{mL}$ for double-stranded DNA).

Amplification of immediate early gene and early gene by PCR
The primers were designed from WSSV DNA replication gene WSV477 (GenBank accession no: DQ121373) [16] and WSSV immediate early gene WSV303 (GenBank accession no: AAL33305) [17]. Corresponding annealing temperature of primers were optimized and it was given in the table 1 . The amplification of the gene was performed in Eppendorf Mastercycler gradient 5331 Version 2.30.31-09. The standard PCR was carried out in a $20 \mu \mathrm{L}$ reaction mixture consisting of $1 \mathrm{X}$ PCR buffer $(50 \mathrm{mM} \mathrm{KCl}, 10 \mathrm{mM}$ Tris-Cl, $\mathrm{pH}$ 8.3), $200 \mu \mathrm{M}$ each of dATP, dTTP, dCTP and dGTP, $10 \mathrm{mM} \mathrm{MgCl}$, 5 pmol of each primer, 1 unit of Taq DNA polymerase (Finnzymes, Espoo, Finland) and $10 \mathrm{ng}$ of WSSV DNA. The cycling condition for Thermal cycler consisted of an initial denaturation at $95^{\circ} \mathrm{C}$ for 5 mins, 35 cycles of denaturation at $95^{\circ} \mathrm{C}$ for 30 secs, annealing at $50^{\circ} \mathrm{C}$ for $30 \mathrm{secs}$ and extension at $72^{\circ} \mathrm{C}$ for 30 secs with a final extension at $72^{\circ} \mathrm{C}$ for 10 mins. The amplified PCR products were electrophoresed in $1.0 \%$ agarose gel stained with ethidium bromide and visualized by ultraviolet transilluminator.

Table 1. Primers used for WSSV detection and gene cloning

\begin{tabular}{|c|c|c|c|}
\hline Primer name & Sequence (5'- 3') & Annealing temperature & Product size \\
\hline WSV 477-F & AAA TCG GGA CAG AAC A & & \\
\hline WSV 477-R & AAA GGG CAC AAC AAA T & $50^{\circ} \mathrm{C}$ & $457 \mathrm{bp}$ \\
\hline WSV 303-F & GTG AAC GCT TGA CTT G & & \\
\hline WSV 303-R & TTT ATA GCC TCC CTG A & $50^{\circ} \mathrm{C}$ & $420 \mathrm{bp}$ \\
\hline 146F1 & ACT ACT AAC TTC AGC CTA TCT AG & & \\
\hline 146R1 & TAA TGC GGG TGT AAT GTT CTT ACG A & $55^{\circ} \mathrm{C}$ & $1447 \mathrm{bp}$ \\
\hline $146 \mathrm{~F} 2$ & GTA ACT GCC CCT TCC ATC TCC A & & \\
\hline 146R2 & TAC GGC AGC TGC TGC ACC TTG T & $55^{\circ} \mathrm{C}$ & $941 \mathrm{bp}$ \\
\hline$\beta$-actin- $F$ & GTG CCC ATC TAC GAG GGA TA & & \\
\hline$\beta$-actin-R & GTG TTG GCG TAC AGG TCC TT & $55^{\circ} \mathrm{C}$ & $404 \mathrm{bp}$ \\
\hline
\end{tabular}

\section{Time course comparative study}

To determine the early detection, different duration muscle tissue of WSSV post-infected P. monodon was collected for examination. The samples were collected at 2, 4, 6, 12, 18 and 24 h.p.i of WSSV infected shrimp. They were analysed for gene expression with WSV303 and WSV477 genes in comparison with OIE-nested PCR method which has been accepted as a standard worldwide. Total RNA was extracted using Trizol (Invitrogen, USA) according to the manufacturer's instructions. cDNA was synthesized from $1.0 \mu \mathrm{g}$ of the total RNA using a One-step Reverse Transcriptase kit (Invitrogen, USA) as per the instructions and used as template for gene expression analysis. $\beta$-actin gene has been used as internal control for the gene expression analysis. Information about the primers used in this 
study has been given in the table 1 . The expected size of the amplified fragment of OIEnested PCR is 941 bp. Positive and negative controls were included in each PCR for validation of the results obtained. PCR conditions of the OIE-nested PCR are fixed as prescribed [13].

\section{Cloning and Sequencing}

The PCR amplicons were purified from agarose gel using DNA purification kit (Bangalore Genei, India) and cloned into the pGEM-T Easy vector (Promega, USA) and transformed into DH5 $\alpha$ (Promega, USA). Recombinants were identified by red-white colored colonies appearing on MacConkey agar (Sigma-Aldrich, USA). Three independent clones were subjected to plasmid DNA extraction using QIAprep Spin Miniprep Kit (QIAGEN, Japan), and sequence was done for the obtained plasmid using ABI prism 377 automated cycle sequencer (Applied Biosystem) and ABI prism dye terminator cycle sequencing kit (Perkin Elmer, CT, USA) at Eurofins Genomics India Pvt. Ltd, Bangalore. The phylogenetic analysis performed on the full-length amino acid sequences of the known molecules using the neighbor-joining ( $\mathrm{NJ}$ ) method was drawn using MEGA 4.0 software [18] and confidence limits were predicted.

\section{RESULTS}

\section{PCR results for immediate early gene and early gene}

Exact annealing temperature of the primer set was found to be $50^{\circ} \mathrm{C}$ (WSV303) and $53^{\circ} \mathrm{C}$ (WSV477). The gene amplification was perfect when it was programmed with 35 cycles. Results showed no band for the template DNA obtained from WSSV-uninfected shrimp. In contrast, in WSSV-infected tissues a band at 420 bp was found for WSV303 (fig. 1) and a band at 457 bp was seen for WSV477 (fig. 2). All the organs from the experimentally infected shrimps were found to be positive for WSV303 (fig. 3) and WSV477 (fig. 4).

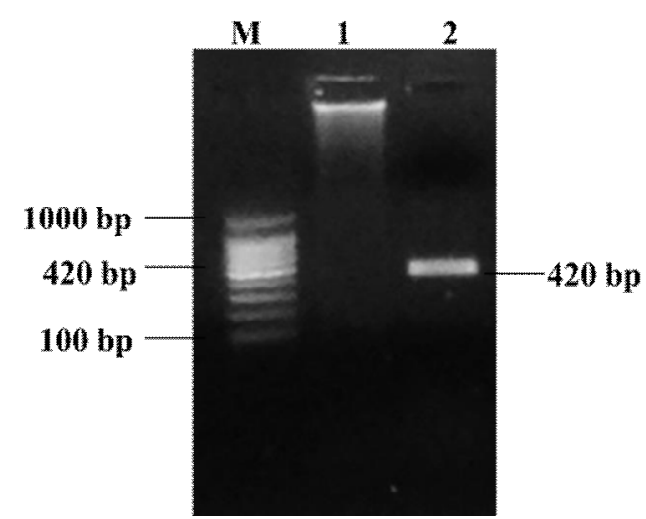

Fig. 1. Agarose gel showing confirmation of WSV303 gene amplification at desired size. M - 100 bp DNA Marker, 1- Uninfected shrimp, 2- Infected shrimp

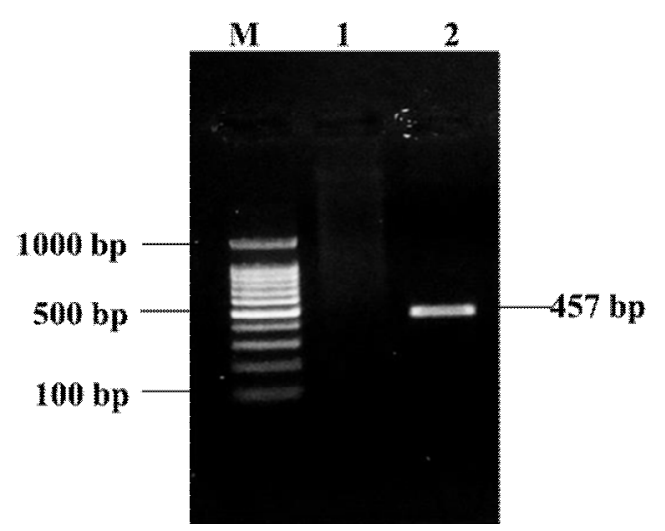

Fig. 2. Agarose gel showing confirmation of WSV477 gene amplification at desired size.

Lane M - 100 bp DNA Marker, Lane 1Uninfected shrimp, Lane 2- Infected shrimp

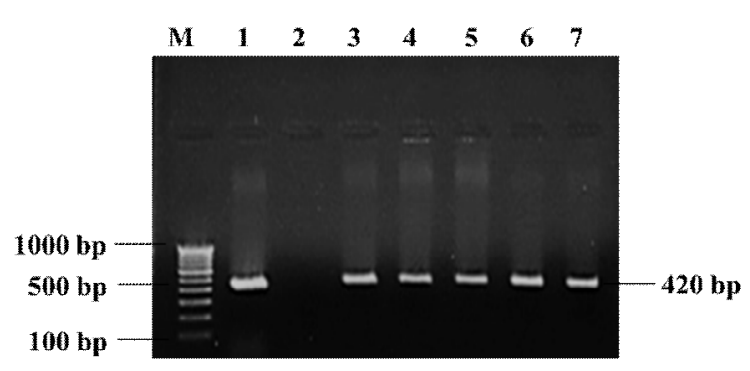

Fig. 3. Agarose gel showing amplification of WSV303 gene from the tissues of experimentally infected Penaeus monodon. M- 100 bp DNA Marker, 1- Positive control, 2- Negative control, 3- Head soft tissue, 4Gills, 5- Heart, 6- Intestine, 7- Tail tissue 


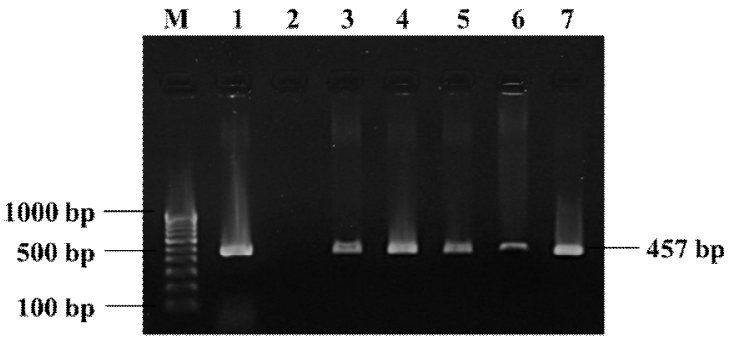

Fig. 4. Agarose gel showing amplification of

WSV477 gene from the tissues of experimentally infected Penaeus monodon.

M- 100 bp DNA Marker, 1- Positive control,

2- Negative control, 3-Head soft tissue,

4- Gills, 5- Heart, 6- Intestine, 7- Tail tissue

\section{Phylogenetic analysis}

The obtained sequences revealed that the homology with other isolates were highly similar. Phylogenetic analysis results revealed that the WSV303 isolate of French coast was found to be in separate cluster, while all other isolates were found in separate cluster (fig. 5) and the WSV477 isolate of Chennai coast was found to be in separate cluster, while all other isolates were found in separate cluster (fig. 6).

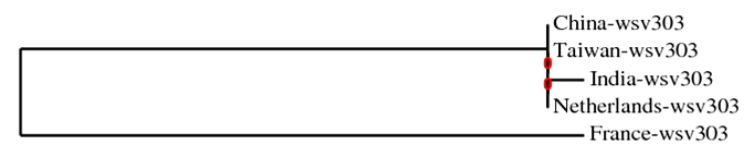

0.2

Fig. 5. Phylogenetic tree of WSV303 Indian isolate and other WSV isolates available from GenBank

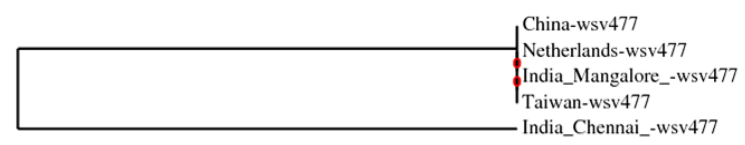

0.2

Fig. 6. Phylogenetic tree of WSV477 Indian isolate and other WSV isolates available from GenBank

\section{Results for time course gene expression study}

The time-course gene expression results revealed that WSV477 and WSV303 is expressing from 2 and 4 h.p.i., respectively (fig. 7). The OIE-nested PCR showed positive from 2 h.p.i onwards (fig. 8).

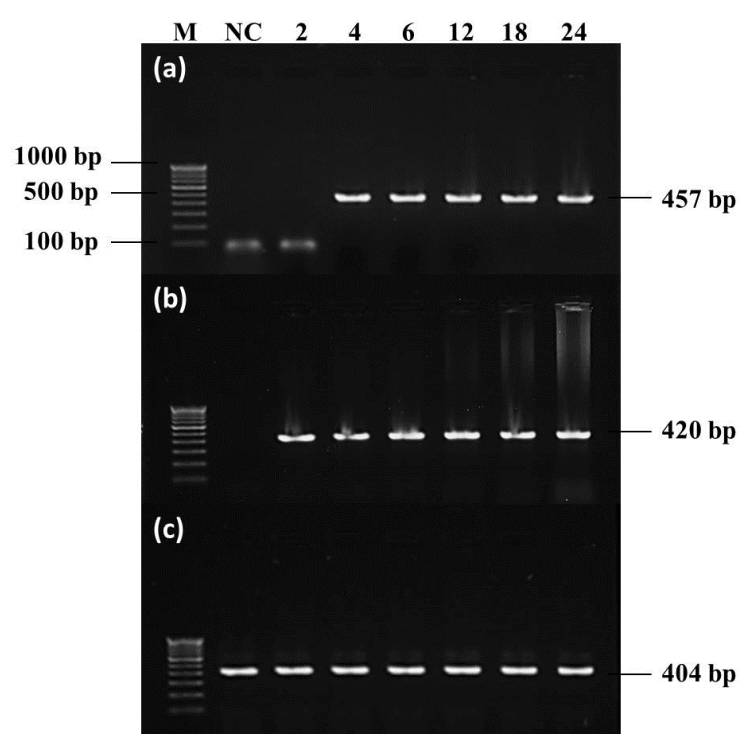

Fig. 7. Agarose gel showing gene expression analysis of WSSV infected muscle tissue.

(a) WSV477; (b) WSV303; (c) $\beta$ - actin (Internal control). 1- 100 bp DNA Marker, 2- Negative control, 3- $2 \mathrm{~h}, 4-4 \mathrm{~h}, 5-6 \mathrm{~h}$, 6- $12 \mathrm{~h}$, Lane 7- $18 \mathrm{~h}, 8-24 \mathrm{~h}$.

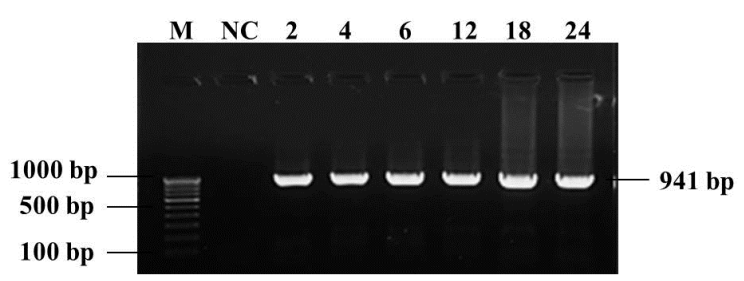

Fig. 8. Agarose gel showing different hour WSSV post infected muscle tissues using OIEnested PCR method. 1- 100 bp DNA Marker,

2- Negative control, 3- 2 h, 4- 4 h, 5- 6 h, Lane 6- $12 \mathrm{~h}, 7-18 \mathrm{~h}, 8-24 \mathrm{~h}$

\section{DISCUSSION}

In this study, the early gene WSV477 and immediate early gene WSV303 of WSSV infected shrimp ( $P$. monodon) were detected by using single step PCR with specific primers for both genes. The WSV477 gene has already been characterized and reported as an early gene and it has GTP binding activity [16].

Time course comparative study for detection and gene expression analysis of 
different duration of post WSSV infected samples revealed that those early and immediate genes are detectable from 4 and 2 h.p.i., respectively. The universally accepted WSSV detection method, OIE-nested PCR showed positive signal from 2 h.p.i onwards. Hence, WSV303 and WSV477 can be used for early detection of WSSV in infected shrimp. Further the PCR product was cloned and sequenced; the homology searches with WSV303 and WSV477 gene products in comparison with other isolates have significant similarity to other known proteins in the GenBank database.

\section{CONCLUSION}

The early gene, WSV477 and immediate early gene, WSV303 are much useful to detect WSSV in the earlier stage of infection in shrimp.

Acknowledgements: R Sudhakaran is a recipient of Young Scientist Award from Science and Engineering Research Board (SERB) of Department of Science and Technology (DST). The authors are grateful to the management of VIT University for providing necessary facilities to carry out this study.

\section{REFERENCES}

1. Wu, W., Wang, L., and Zhang, X., 2005. Identification of white spot syndrome virus (WSSV) envelope proteins involved in shrimp infection. Virology, 332(2): 578-583.

2. Leu, J. H., Yang, F., Zhang, X., Xu, X., Kou, G. H., and Lo, C. F., 2009. Whispovirus. In Lesser Known Large dsDNA Viruses (pp. 197-227). Springer Berlin Heidelberg.

3. Natividad, K. D. T., Nomura, N., and Matsumura, M., 2008. Detection of White spot syndrome virus DNA in pond soil using a 2-step nested PCR. Journal of virological methods, 149(1): 28-34.

4. Wang, Y. G., Hassan, M. D., Shariff, M., Zamri, S. M., and Chen, X., 1999. Histopathology and cytopathology of white spot syndrome virus (WSSV) in cultured Penaeus monodon from peninsular Malaysia with emphasis on pathogenesis and the mechanism of white spot formation. Diseases of aquatic organisms, 39(1): 1-11.
5. Sudheer, N. S., Philip, R., and Singh, I. B., 2012. Anti-white spot syndrome virus activity of Ceriops tagal aqueous extract in giant tiger shrimp Penaeus monodon. Archives of virology, 157(9): 1665-1675.

6. Jensen, O. N., Houthaeve, T., Shevchenko, A., Cudmore, S., Ashford, T. O. N. Y., Mann, M. A. T. T. H. I. A. S., Griffiths, G., and Locker, J. K., 1996. Identification of the major membrane and core proteins of vaccinia virus by two-dimensional electrophoresis. Journal of virology, 70(11): 7485-7497.

7. Ma, G., Yu, L., Wang, Q., Liu, W., Cui, Y., and Kwang, J., 2012. Sf-PHB2, A new transcription factor, Drives WSSV Ie1 Gene Expression via a 12-bp DNA Element. Virology journal, 9(1): 206.

8. Liu, W. J., Chang, Y. S., Wang, C. H., Kou, G. H., and Lo, C. F., 2005. Microarray and RT-PCR screening for white spot syndrome virus immediate-early genes in cycloheximide-treated shrimp. Virology, 334(2): 327-341.

9. Li, L., Lin, S., and Yanga, F., 2005. Functional identification of the non-specific nuclease from white spot syndrome virus. Virology, 337(2): 399-406.

10. Chang, P. S., Chen, L. J., and Wang, Y. C., 1998. The effect of ultraviolet irradiation, heat, $\mathrm{pH}$, ozone, salinity and chemical disinfectants on the infectivity of white spot syndrome baculovirus. Aquaculture, 166(1): 1-17.

11. Okano, K., Mikhailov, V. S., and Maeda, S., 1999. Colocalization of baculovirus IE-1 and two DNA-binding proteins, DBP and LEF-3, to viral replication factories. Journal of virology, 73(1): 110-119.

12. Lo, C. F., Ho. C., Peng, S., Chen, C. H., Hsu, H., Chiu, Y., Chang, C., Liu, K., Su, M., Wang, C., 1996. White spot syndrome baculovirus (WSBV) detected in cultured and captured shrimp, crabs and other arthropods. Diseases of Aquatic Organisms, 27, 215-225.

13. Lo, C. F., Leu, J. H., Ho, C. H., Chen, C. N., Peng, S. E., Chen, Y. T., Chou,C. M., 
Yeh, P. Y., Huang, C. J., Chou, H. Y., Wang, C. H., and Kou, G. H., 1996. Detection of baculovirus associated with white spot syndrome (WSBV) in penaeid shrimps using polymerase chain reaction. Diseases of aquatic organisms, 25, 133141.

14. Sánchez-Paz, A., 2010. White spot syndrome virus: an overview on an emergent concern. Veterinary research, 41(6): 43.

15. Manjanaik, B., Umesha, K. R., Karunasagar, I., and Karunasagar, I., 2005. Detection of hepatopancreatic parvovirus (HPV) in wild shrimp from India by nested polymerase chain reaction
(PCR). Diseases of aquatic organisms, 63, 255-259.

16. Han, F., Xu, J., and Zhang, X., 2007. Characterization of an early gene (wsv477) from shrimp white spot syndrome virus (WSSV). Virus genes, 34(2): 193-198.

17. Lin, F., Huang, H., Xu, L., Li, F., and Yang, $F$., 2011. Identification of three immediateearly genes of white spot syndrome virus. Archives of virology, 156(9): 1611-1614.

18. Tamura, K., Dudley, J., Nei, M., and Kumar, S., 2007. MEGA4: molecular evolutionary genetics analysis (MEGA) software version 4.0. Molecular biology and evolution, 24(8): 1596-1599. 